\title{
STRATEGIC FIRMS AND ENDOGENOUS CONSUMER EMULATION*
}

\author{
Philipp Kircher ANd ANDRew Postlewaite
}

\begin{abstract}
Better-informed consumers may be treated preferentially by firms because their consumption serves as a quality signal for other customers. For normal goods this results in wealthy individuals being treated better than poor individuals. We investigate this phenomenon in an equilibrium model of social learning with heterogeneous consumers and firms that act strategically. Consumers search for highquality firms and condition their choices on observed actions of other consumers. When they observe consumers who are more likely to have identified a high-quality firm, uninformed individuals will optimally emulate those consumers. One group of consumers arise endogenously as "leaders" whose consumption behavior is emulated. Follow-on sales induce firms to give preferential treatment to these lead consumers, which reinforces their learning.
\end{abstract}

"One very clear impression I had of all the Beautiful People was their prudence. It may be that they paid for their own airline tickets but they paid for little else."

James Brady, Press Secretary to Ronald Reagan

From Superchic, Little, Brown 1974

\section{INTRODUCTION}

Hollywood actors who participate in the Oscar ceremonies receive free gifts—called swag-worth more than $\$ 100,000$. Not just superstars get treated so well: affluent Ford and Audi customers receive special service, Silicon Valley experts receive high-tech equipment for free, ski instructors receive winter clothing and ski-wear at substantially reduced prices, and amateur triathletes get their running equipment subsidized by manufacturers. Why are these groups treated better than other consumers of the same product? We argue that there are informational spillovers that yield returns to consumers with superior information.

* Earlier versions of this paper circulated under the titles "Why Do the Rich Get More Than They Pay for?" and "Why Are the Wealthy Treated So Well?" The paper benefited from many discussions with George Mailath. We thank Ken Burdett, Georg Nöldeke, and Randy Wright for insightful comments. We also thank Ed Glaeser and anonymous referees for many helpful suggestions. This paper was presented at a number of universities, at the conference in Honor of Jean-Jacques Laffont, and at the Society of Economic Dynamics conference at Paris; we thank the participants of those presentations for helpful comments. We are grateful to Roberto Pinheiro for valuable research assistance. Postlewaite thanks the National Science Foundation (Grants SES-0095768 and SES-0527656) for financial support.

(C) 2008 by the President and Fellows of Harvard College and the Massachusetts Institute of Technology.

The Quarterly Journal of Economics, May 2008 
Consider Ford's promotional effort toward their VIP clients. The purpose is not only to sell to this target group but to reach a wider customer base. In their "VIP program" to market the Thunderbird, Ford targeted affluent consumers seriously interested in automobiles. Eighty-four percent of these "knowledgeable car buffs" acted as sources of information to other buyers. ${ }^{1}$ Convincing this lead group affects sales far beyond their own purchases.

In the case of swag for actors, clearly media visibility is important. Nevertheless, it is revealing that many of the free products fall into classes about which actors arguably know more than almost anyone else: cosmetics, clothing and accessories, and vouchers for travel and hotel resorts. ${ }^{2}$ Even if the products are free, actors will not use them unless they meet presumably high quality standards. Using a swag product consequently sends a positive signal about it to the larger market. Most products relate to an area of their expertise and the informational value is important. Similarly, ski instructors receive large discounts on skiing equipment precisely because of their role as "opinion leaders" based on their presumed superior information and experience in this market (German Ski Instructor Association 2006).

Heterogeneous consumers will typically have different propensities to acquire information. We derive these differences endogenously and provide an analysis of the interplay between

1. information accumulation by consumers;

2. the way consumers learn from the consumption choices of others; and

3. the firms' decisions to provide discriminatory service (or rebates) to select consumers.

We model consumers who are initially uninformed about firms' qualities but learn a firm's quality after purchasing. Some individuals consume more frequently than others and hence are likely to be better informed. When uninformed consumers can identify frequent purchasers, they will optimally emulate them. ${ }^{3}$ Plan."

1. Wall Street Journal, 10/17/1983: "Ford Pushing Thunderbird With VIP

2. USA Today, 02/21/2005: "Oscar Isn't the Only Gold Handed Out."

3 . The idea that quality might only be verified through purchases and subsequent consumption goes back at least to Nelson's (1970) concept of experience goods. He suggests that the pattern of an individual's repeated purchases might not be random but might incorporate the information of others, a process he terms guided sampling. We formalize the idea that guided sampling might evolve endogenously with firms strategically engaged in the process. 
Because of the follow-on business of these frequent purchasers, firms will reward them with better service than they might otherwise receive. Indeed, the cost of service may make the transaction with a frequent purchaser unprofitable on its own. Sales to these more frequent purchasers are essentially loss-leaders.

In our model consumers are heterogeneous with respect to income, which we assume to be observable. The good of unknown quality is normal, so the relatively wealthy consume more frequently and acquire information more quickly. Consumers observe the choices of some other customers in the market, which is potentially informative. Individuals who have not found a high-quality seller have an incentive to buy from the same firms as the customers they observe, in the hope that those customers have identified a high-quality seller; at worst, the observed customers are still searching randomly and following them is the same as randomly searching on one's own. When there is a choice about whom to follow it pays to follow consumers who have most likely identified a high-quality seller; those consumers will be rich because the rich acquire information more quickly than the poor.

We focus on differences in income as the source of heterogeneity between consumers for several reasons. First, there is evidence that higher-income individuals tend to be opinion leaders (see, e.g., Assael [1984] and Robertson, Zielinski, and Ward [1984]). Second, even if income or wealth might be difficult to observe and may need to be inferred from secondary characteristics (dress, car model, brand of watch, etc.), this might still be easier than to observe other agents' tastes. What is crucial is that sellers and other consumers can observe something about those buyers who have more information. ${ }^{4}$

Differences in preferences can lead some people to consume more often and, consequently, to acquire more information in the market than others. To the extent that differences in preferences are observable - as in the example of ski instructors-there is a role for providing service based on preferences rather than on income. We will treat this case as well: Preference differences affect consumption frequency analogously to income differences; consequently our results provide insights in both cases. In general, consumer heterogeneity that leads to one group consuming more frequently results in differentially informed consumers, and the

4. In the Discussion we outline how conspicuous consumption may arise when wealth must be inferred rather than being directly observed. 
uninformed will mimic the choices of frequent consumers. ${ }^{5}$ The result is that those known to have better information will be given preferential treatment.

We abstract from three important aspects for the sake of simplicity: the importance of being famous, the role of conspicuous consumption, and conflicting interests between consumer groups. Extending our analysis to the case in which some people are more easily observed than others would yield a market value to being popular. Conspicuous consumption becomes relevant in environments in which an agent's type cannot easily be distinguished. In this case more affluent agents would like to distinguish themselves from the others in order to reap the benefits of their status in other transactions. Finally, although in our model agents agree in their evaluation of the product, one could extend it to a world with different opinions. People may have different views about what constitutes an attractive ambience for a restaurant, while all agents agree about the quality of the food. If leaders consume often enough, they will search for high levels on both dimensions. Followers do not consume so frequently and might simply follow the leaders, ending up in places in which they dislike the second dimension. Firms will choose the provision of the second dimension to attract the leaders and their tastes determine the style of the ambience even if they constitute a small part of a firm's business. In this way our model captures Becker and Murphy's (2000) idea of the "tyrannical power" that social forces have over individual behavior. In our extended setup the leaders dictate the second product dimension, and in this sense constitute a dictatorship of the informed. ${ }^{6}$

In the following section we provide support for the assumptions that underlie our model. We present the model and its equilibrium implications in Section III. Section IV discusses specific features of the model and relates it to the literature. We conclude by comparing our results to alternative explanations of emulation based on the followers' desire simply to mimic the leaders in order to achieve higher social status. Our model has testable differences in predictions. For example, it is consistent with leadership of female rather than male consumers (Feick and Price 1987) and can

5. Mimicking behavior may be moderated when there are substantial taste differences between frequent consumers and less frequent consumers about quality. A stereo aficionado may be willing to pay more for esoteric equipment than an average music enthusiast.

6. We thank the editor for bringing this point to our attention. 
account for cases in which the poorer or lower classes are opinion leaders if the good in consideration is an inferior good. Omitted proofs and derivations are provided in the Appendix.

\section{Emulating Consumers}

Our model entails three key features. (1) Consumers infer quality from the choices of other consumers. (2) Some consumers hold or acquire more information than others and therefore make more informed choices. (3) Firms provide these lead consumers with preferential treatment or price reductions to foster indirect advertising of their product. We discuss these in turn.

Psychology and marketing have long understood that consumers infer product quality from the actions of others. Venkatesan (1966) provides a classical experiment in this vein. Male subjects are presented with three dress suits and are instructed to choose the highest-quality suit. In the base treatment they choose on their own, whereas in the control treatment they choose in the presence of others who are instructed to all agree that the second suit is the best. In the control treatment subjects are significantly more likely to choose the second suit than in the base treatment. Replications of the study and follow-ups with other products confirm these findings. ${ }^{7}$ Although social pressure to conform-rather than informational inference-is sometimes cited as another explanation, the results are replicated in a setting where the individual decides without being observed by others (Burnkrant and Cousineau 1975). Information transmission between buyers has also been explored in economic settings: Foster and Rosenzweig (1995) show the importance of information transmission for product adoption of farmers, and Mobius and Niehaus (2005) conduct a randomized experiment in a consumer product market and find significant effects of social learning about product and service characteristics.

The informational influence consumers have on others depends on their knowledge of the subject. When a trait that correlates with knowledge is observable, people follow the knowledgeable. Commercial marketers regularly use the association with knowledgeable people in advertising strategies, often featuring amateur or professional athletes endorsing sports equipment. More striking are campaigns based on stereotypes.

7. See for example Sims (1971) and Cohen and Golden (1972). 
Daimler-Chrysler's recent advertising campaign heavily uses an announcer with a German accent in stressing the engineering of Chryslers. ${ }^{8}$ Supposedly Germans know about cars. Similarly, the French brand LU uses an American accent in French television commercials to promote their chocolate chip cookies (Martin 2002).

While marketers use stereotypes in advertising, the impact of informational sources on consumer behavior depends on the credibility of the source of the information. Actual consumer choices are particularly credible. ${ }^{9}$ Consistent with our model, firms extend special efforts to sell to opinion leaders. Ford's VIP campaign described in the introduction falls into this category. Similarly, Adidas sponsors local soccer players through rebates on soccer shoes, local tennis amateurs receive free rackets from suppliers, and Reebok sponsors 40 "local heroes"-runners and triathletes and several regional running clubs-through equipment support (McDonald and Milne 1999). These effects are obviously magnified when the visibility of the athletes is increased in the professional sports. The encouragement of special consumer classes to consume one's products for advertising reasons is not limited to sports. Some young people are considered more knowledgeable about fashion, and some department stores and clothing retailers give substantial discounts to young people whom they identify as opinion leaders (Engel, Blackwell, and Miniard 1995).

The case of product placements to celebrities is particularly striking. As mentioned in the Introduction, the free product package given at the Oscars has a market value of $\$ 100,000$. Interestingly, many products in the gift basket are products about which stars are likely to be knowledgeable: cosmetics, travel vouchers, hotel accommodations. ${ }^{10}$ Other free gifts include the provision of dresses, loaned jewelry, and similar products. ${ }^{11}$ The value of the swag is such that the IRS has begun requiring the declaration

8. Detroit News Online, 7/25/06; “'Dr. Z' Ads Put German Accent On 'Buy American.'”

9. This is most obvious for outfitters such as Burberry or Wolsey that take special pride in their sales to their most influential customer: the British royal court. Providers to the royal court commit to highest quality and service provision, which can earn them a Royal Warrant, an institutionalized way of informing the market. A Royal Warrant is only granted after at least five years of satisfactory consumption experience by a member of the royal family, ensuring that quality and service indeed meet court standards, and conveys a signal of quality. According to the Royal Warrant Holders Association (2006), the warrants are highly prized and are viewed as a mark of excellence and quality in the general marketplace.

10. USA Today, 02/21/2006: "Oscar Isn't the Only Gold Handed Out."

11. Los Angeles Times, 02/28/06: "She's Ready for Her Close-up." 
of these gifts as taxable income. ${ }^{12}$ The combination of actors' information about the products and the wide visibility of the usage makes celebrities especially attractive users of these products, resulting in especially generous treatment of these users. Similar product giveaways take place in Silicon Valley, where top executives are given new high-tech products for their personal use with the explicit goal of influencing the broader public. ${ }^{13}$ Doctors and dentists are obvious targets of giveaways, given their visibility and presumed knowledge. Advertisers even resort to the wives of dentists to recommend toothpaste when featuring real doctors is prohibited by law, and spouses of dermatologists are targeted by free samples of skin care products. ${ }^{14}$

For many activities that are the focus of this paper, special treatment to opinion leaders is less well documented because the magnitudes are smaller. Some of the preferential treatment that restaurants give to their more affluent clientele in terms of seating and service might be attributable to the importance these consumers have in generating business by others who mimic their choices. For some items such as wine and high cuisine, opinion leadership of connoisseurs is well established (Chaney 2001), and their preferential treatment is widely known.

We focus on information transmission between consumers and the service this generates for the informed consumer group, but our results also shed light on business-to-business relationships. The use of some product by a firm might give valuable information to other firms that are interested in the same product. The software giant SAP specializes in business software solutions. Their marketing strategy, "The Best Run Businesses Run SAP," is centered on their successful implementation with presumably knowledgeable lead consumers. It features key clients such as Palm Inc., Goodyear, or Avid Technology Inc. and their success stories in using SAP products (see SAP [2006]). Although SAP fosters the transmission of information through marketing, the key features of our model apply here. There are some business consumers who gather information with the SAP product. Other consumers look to them when making a purchase decision. The

12. Time Magazine, 08/17/06: "Even Stars Have to Pay Taxes."

13. Newsweek, 01/21/2005: "The Connected Get More Connected: Seeking Buzz, Companies Will Funnel Free New Products to Silicon Valley's Elite."

14. See Hoyer and Macinnis (2001) for reference to the advertising campaign. Information on determatologists was communicated to us by a participant at the American Academy of Dermatology 63rd Annual Meeting. 
presence of the lead customers lends credibility to SAP, generating follow-up business. The lead customers are key accounts that are managed with special care.

\section{The ModeL}

There are a countably infinite number of periods, a continuum $I$ of consumers, and a continuum $J$ of firms. Consumers have constant per-period income, which is nonstorable, and are heterogeneous with respect to this income. Each consumer $i \in I$ has a type $\theta_{i} \in\{p, w\}$, indicating whether he is poor or wealthy. The proportion of wealthy consumers is $\alpha \in(0,1)$, and each of them has income $y_{w}$. Poor consumers have income $y_{p}<y_{w}$.

Firms are infinitely lived and heterogenous with respect to the quality $q \in\left\{q_{l}, q_{h}\right\}, q_{l}<q_{h}$, of the otherwise identical indivisible good they produce. We denote the proportion of firms with quality $q_{h}$ by $\lambda \in(0,1)$.

Consumers' types are observable. A firm's type is initially known only to the firm and is fully revealed to a consumer after consumption of the firm's output. Consumers die each period with probability $(1-\delta)$; when a consumer dies, a new consumer of the same type is born; new agents know only the proportion of highquality firms.

\section{III.A. The Firm's Problem}

Each firm $j \in J$ supplies an indivisible good, the quality of which is exogenous and unchanging over time. The market price of the good, $P>0$, is exogenously given and identical for all firms. ${ }^{15}$ Our focus is on firms' efforts to attract customers, and for simplicity we assume that the good can be produced costlessly. The firm chooses whether to provide service to a given customer; we denote the level of service by $s \in\{0, \bar{s}\}, \bar{s}>0$, where 0 denotes no service. At the time of service provision, the customer is already locked in and cannot switch to a competitor in the current period. The cost $c(\bar{s})$ of providing service is $c>P$ and is incurred in the period in

15. Taking prices as exogenously given allows us to focus on private information that is not fully revealed through prices. That prices do not reveal all relevant information about products is widely accepted, and strong restrictions on pricing behavior are therefore common in models of this sort to preclude revelation of too much information (see, for example, Wolinsky [1990]). We discuss the possibility of price competition and argue that the price could be endogenized without qualitatively affecting our results under some out of equilibrium beliefs in Section IV. 
which the service is provided. There is no cost to the firm if service is not provided: $c(0)=0$.

Firms can commit to any current customer to give service the next time he returns. ${ }^{16}$ More specifically, we model firm $j$ 's choice $s_{j, i}^{t}$ in period $t$ for consumer $i$ as representing the firm's one-period-ahead service commitment. $s_{j, i}^{t}$ is the promise to provide this service level in the first period $\tau>t$ when the customer returns. We assume that first-period service is zero because it is the promise of future service that affects consumers' behavior. Let $I_{j}^{t}$ be the set of consumers who purchase from firm $j$ in period $t$, and $\hat{s}_{j, i}^{t}$ the service that firm $j$ actually provides to consumer $i$ in period $t$. Firm $j$ 's per period profit is

$$
\pi_{j}^{t}=\int_{i \in I_{j}^{t}} P-c\left(\hat{s}_{j, i}^{t}\right) d i .
$$

Firms maximize the discounted present value of per-period profits, $\sum_{t=0}^{\infty} \beta^{t} E \pi_{j}^{t}$.

The cost of the provision of service is shown in the per-period profit expression above, whereas the benefits are indirect. A firm that promises service to an individual consumer may deter the consumer from switching to a competitor or may hasten his return. Furthermore, the consumer's choice may affect the future choices of other consumers. These (potential) benefits to a firm that provides service are reflected in the size of the set of consumers who consume at the firm in the future. As a tie-breaking rule we assume that firms offer service when indifferent.

\section{III.B. The Consumer's Problem}

Consumers are heterogeneous with respect to income, but all can afford the product: $y_{w}>y_{p}>P$, where $y_{w}$ and $y_{p}$ are, respectively, the wealth of the rich and the poor. In each period $t \in T$, consumer $i \in I$ has two choices: to enter the market or not, and if entering the market, from which firm to consume. If he does not enter, he spends his income on a numeraire good. Income is nonstorable and the price of the numeraire is normalized to one; that is, a consumer with income $y$ obtains $y$ units of the numeraire in the case where he does not consume in the market, and $y-P$ units if he does.

16. We allow one-period-ahead commitment in order to eliminate implausible equilibria. Without commitment there is always an equilibrium in which a firm does not provide service because the firm cannot convince the customer that he will also get service in the future. 
At the beginning of each period, before the consumption decision is made, a taste shock $\rho$ is realized for each consumer that affects the degree to which he enjoys consuming the indivisible good in that period. We assume that shocks are independent draws from distribution $F$ with density $f$ and full support on $[\rho, \bar{\rho}]$, where $-\infty \leq \rho<\bar{\rho} \leq \infty$. If the consumer decides to enter the market and consume from firm $j$ in period $t$, his utility in that period is

$$
U^{t}=q_{j}+\hat{s}_{j}^{t}+\rho^{t}+u(y-P),
$$

where $q_{j}$ is the quality of firm $j$, $\hat{s}_{j}^{t}$ is the service that he receives, and $\rho^{t}$ is the current-period taste shock. $u(\cdot)$ denotes the utility derived from the numeraire, which is assumed to be increasing and strictly concave.

If the consumer is uninformed and chooses a firm randomly, his expected utility is

$$
E U^{t}=E_{j}\left[q_{j}\right]+\rho^{t}+u(y-P) .
$$

If the consumer decides not to consume, his utility for that period is $U^{t}=u(y)$. Consumers maximize the expected discounted utility $\sum_{t=0}^{\infty} \delta^{t} E U^{t}$, where $\delta \in(0,1)$ is the probability of survival.

We assume that observing other consumers' behavior partially substitutes for an individual's initial lack of information about product qualities. After the first time a consumer purchases the indivisible good, he can costlessly observe at which firm a random wealthy consumer and a random poor consumer consumed in the previous period. ${ }^{17,18}$ Thus, only players who participated in the market in the previous period are observable. For ease of exposition we assume that if a consumer is indifferent between following other participants' choices observed at different periods, he follows the most recent observation.

The combination of the numeraire good as an alternative to market consumption and the taste shock capture the idea that

17. If all consumers observe other participants' choices and mimic those choices, no one will be searching randomly and eventually only high-quality firms will be frequented. Assuming that newborn consumers only observe another consumer's choice after they consume once ensures that there will always be a positive proportion of consumers who search randomly. One could replace this assumption with an assumption that in each period a positive proportion of consumers do not observe another consumer's choice, and hence must choose randomly. Our assumption leads to simpler computations.

18. Observing more than one player of any type does not alter any results. Observing only a random selection of $N$ players' choices, each period would not alter any qualitative results as long as $N$ is sufficiently large. 
the good is a normal good. The opportunity cost of going into the market is

$$
u_{0}:=u(y)-u(y-P)
$$

that is, the utility of foregone consumption of the numeraire good. Denote this opportunity cost as $u_{0}^{w}$ for the wealthy and $u_{0}^{p}$ for the poor. The strict concavity of $u(\cdot)$ then implies that $u_{0}^{w}<u_{0}^{p}$. That is, the wealthy have a lower opportunity cost of entering the market because they get less additional utility by spending the money otherwise. ${ }^{19}$ Without service the wealthy will therefore enter the market for lower values of the taste shock than the poor. Thus, on average the wealthy consume more often, which establishes our version of the normal goods assumption. ${ }^{20}$

The taste shock also allows firms to encourage the customer to consume more frequently. The timing of when to consume in the market is not exogenously fixed, but rather depends on the current-period taste shock and the utility of consumption. By promising service, the firms can raise the utility of consumption and can thus encourage a consumer to consume more frequently.

Our focus is on the case where $c>P$, which is the interesting case in which no consumer will receive service only because of his own consumption. Firms will only provide service because a consumer brings in additional customers who follow his lead. This case clearly highlights the effects of information transmission in the market.

\section{III.C. Stationary Equilibrium}

We are interested in equilibria in which firms and consumers base their decisions only on information that is relevant for their future payoffs. We restrict attention to strategies that depend on the type (i.e., wealthy or poor) but not on the name of other players. For firms, the minimal payoff relevant information is the type of the consumer, and we consider equilibrium strategies $s(\theta)$ in which the service commitment of a firm is a function of the

19. Players get in each period $y-P$ units of the numeraire for sure, independent of their current period choice. Therefore wealthy players' consumptionindependent level of the numeraire is higher. Only the additional amount that they might get, that is, their opportunity cost, is lower. The term $u(y-P)$ in the utility function will be dropped for all subsequent calculations as it only reflects a constant.

20 . Heterogeneity in the opportunity costs of consumption (rather than heterogeneity in terms of income) can be taken as primitive to allow for more general interpretations of the model. See Section IV for a discussion. 
consumer's type. We consider symmetric pure strategies; that is, $s(\theta)$ is deterministic and the same for firms of the same type. We denote such a strategy by $s_{l}(\cdot)$ for low-quality firms and by $s_{h}(\cdot)$ for high.

For a consumer, the relevant information is the combination of quality and service he can obtain; the name of the firm from which he can receive some combination is not important. Consequently, a consumer conditions his actions on the set of quality-service pairs, which we denote as $D \subseteq\left\{q_{l}, q_{h}\right\} \times\{0, \bar{s}\}$. For example, if $D$ includes a pair $\left(q_{l}, 0\right)$, it means that the consumer knows a firm with quality $q_{l}$ that has not offered him service for the next time he returns. If the consumer has not yet purchased, $D=\emptyset$. A strategy for a consumer of type $\theta \in\{p, w\}$ is then a pair $\left(\hat{\rho}^{\theta}(D), \sigma^{\theta}(D)\right)$ for each $D$. The term $\hat{\rho}^{\theta}(D)$ denotes a threshold for the taste shock: If the taste shock is above $\hat{\rho}^{\theta}(D)$, the consumer buys the product, otherwise he does not. ${ }^{21}$ If he chooses to buy, $\sigma^{\theta}(D)$ specifies his purchase decision. If $D \neq \emptyset$, then the consumer can obtain quality-service combination $(q, s) \in D$ at a firm he already visited, he can follow the choice of either a wealthy or a poor consumer observed in the previous period, or he can search randomly for a new firm. If $D=\emptyset$ only the last option is available, as by assumption the consumer must search randomly in the first period of consumption.

Let $n^{\theta, t}(D)$ denote the proportion of type $\theta$ consumers with information $D$ at time $t$, where the law of motion is determined by the strategies of consumers and firms. With this we can define a stationary equilibrium.

DEFINITION 1 (Stationary Equilibrium). A stationary equilibrium is a vector of strategies and steady state proportions $S=$ $\left(s_{l}, s_{h},\left(\hat{\rho}^{w}, \sigma^{w}\right),\left(\hat{\rho}^{p}, \sigma^{p}\right), n^{w}, n^{p}\right)$ such that

1. Consumer Optimality: For each consumer of type $\theta$, strategy $\left(\hat{\rho}^{\theta}, \sigma^{\theta}\right)$ is optimal in the continuation game for all $D$, when the consumer takes as given the strategies and fractions of the other players as summarized in $S$.

2. Firm Optimality: For each high (low)-quality firm $s_{h}\left(s_{l}\right)$ is optimal given $S$.

3. Stationarity: $n^{\theta, t}(D)=n^{\theta}(D) \forall t \forall D \forall \theta$.

21. In the Appendix we show that threshold strategies are optimal in our environment. 


\section{III.D. Optimal Behavior}

To characterize the equilibria of this game we discuss optimal choices by consumers first, then optimal choices of firms, and finally we integrate the two.

Consumer Search. We first analyze the optimal consumption decision for a consumer with opportunity cost $u_{0}$, which determines his frequency of consumption. Fix the strategy of the firms and suppose that all high-quality firms offer this consumer identical service $s$ (either $\bar{s}$ or zero) in every period, and low-quality firms do not offer more service than high-quality firms. ${ }^{22}$ Assume that the consumer has entered the market at least once, so that he has observed other participants in the market. If the consumer has not found a high-quality firm and chooses to purchase from a firm not previously frequented, there is a probability $\gamma$ that this firm will be of high quality. Take for now as exogenous the process by which this consumer chooses a new firm, and hence $\gamma$.

The consumer's problem is a standard search problem with one exception - the consumer only searches in periods in which his taste shock is sufficiently high. His decisions about how frequently to search and how to choose firms given the frequency of search are linked: an individual who consumes more frequently will be more likely to search for a combination of high quality and service, and higher quality or service induces higher frequency of search.

The optimal strategy for the consumer once he has found a high-quality firm is to consume whenever his taste shock exceeds the threshold $\hat{\rho}_{h}=u_{0}-q_{h}-s$. This threshold is intuitive: He gets either his outside option $u_{0}$ or his consumption utility $q_{h}+s+\rho$, and he is indifferent if $u_{0}=q_{h}+s+\hat{\rho}_{h} \cdot{ }^{23}$ If the consumer has not found a high-quality firm, the threshold at which he will consume, $\hat{\rho}_{l}$, has a similar structure but incorporates the informational value of experimentation (see Lemma 1 in the Appendix). We will focus on a consumer who is sufficiently patient so that he will continue searching until he finds a high-quality

22. We will show that it is always profitable for a high-quality firm to provide service if it is profitable for a low-quality firm to provide service.

23. To ensure that a threshold exists that leads to indifference, we assume that the support of the taste shock satisfies the following: $(\underline{\rho}, \bar{\rho}) \supset\left[u_{0}^{w}-q_{h}-\bar{s}, u_{0}^{p}-q_{l}\right]$. This implies that $\rho+q_{h}+\bar{s}<u_{0}^{w}$, so that even in the most advantageous situation of high quality and high service, there are taste shocks sufficiently low so that not consuming is preferable. Analogously, even in the most disadvantageous situation some taste shocks still induce the consumer to enter the market. 
firm if all firms offer service, that is, on consumers for whom the survival probability $\delta \geq \underline{\delta}$ for some $\underline{\delta}{ }^{24}$

These thresholds for consumption depend on the opportunity cost of consumption, which is lower for the wealthy than for the poor. Therefore, if wealthy and poor consumers are treated equally by firms, the wealthy will consume more frequently both before and after identifying a high-quality firm (Lemma 3 in the Appendix). This is essentially a restatement of our formulation of the normal goods assumption. If the wealthy receive service whereas the poor do not, the gap between the frequencies with which the two groups search is amplified. Only if service is given only to the poor and the impact of service outweighs the difference in the opportunity costs of consuming is it possible that the poor consume more frequently than the wealthy.

If consumers from some group purchase more frequently, they will be the leaders, as they on average possess better information. Let $\gamma^{w}$ and $\gamma^{p}$ be respectively the proportions of the wealthy and the poor who have identified a high-quality firm. The following proposition formalizes the conditions under which following the wealthy is preferable to following the poor.

Proposition 1. Let $\delta \in(\underline{\delta}, 1), \gamma \in(\lambda, 1)$, and assume that highquality firms provide weakly higher service to consumers $\left(s_{h}(\cdot) \geq s_{l}(\cdot)\right)$. Then there exists $\hat{v}_{\gamma}>u_{0}^{p}-u_{0}^{w}$ such that

(i) If the rich receive weakly higher service from high-quality firms than the poor $\left(s_{h}(w) \geq s_{h}(p)\right)$ or if service is not very important $\left(\bar{s}<\hat{v}_{\gamma}\right)$, then the rich generate a better signal $\left(\gamma^{w}>\gamma^{p}>\lambda\right)$.

(ii) If the poor receive strictly more service from high-quality firms than the rich $\left(s_{h}(p)>s_{h}(w)\right)$ and service is very important $\left(\bar{s}>\hat{v}_{\gamma}\right)$, then the poor generate a better signal $\left(\gamma^{p}>\gamma^{w}>\lambda\right)$.

Note that following any consumer, wealthy or poor, is strictly preferable to searching randomly. At worst, the consumer who is followed has not found a high-quality firm yet, in which case the firm he or she purchased from is as likely to be high-quality as a randomly sampled firm. In addition, there is a positive probability

24. The consumer foregoes service while searching, which could deter him from searching when service is important and his discount factor is low. If the importance of service relative to quality is not too large, the consumer would want to search at any discount factor. Lemma 2 in the Appendix presents the formal argument. 
that the consumer who is being mimicked has found a high-quality firm and purchases only from that firm. Second, all consumers sample in a way that gives the highest probability of identifying a high-quality firm. Thus, both the uninformed wealthy consumers and the uninformed poor follow the same group and face the same (endogenous) probability $\gamma$ of finding a high-quality firm.

The calculations of $\gamma^{w}$ and $\gamma^{p}$, the proportions of the two groups who had identified a high-quality firm, were based on a given probability $\gamma$ of finding a high-quality firm when searching. When searching consumers are following a particular group, the probability $\gamma$ must equal the proportion of that group who have identified a high-quality firm. We prove the existence of such a fixed point in the Appendix (Lemma 4).

Firms' Behavior. We turn to service provision by the firms. We will show that it is profitable for a high-quality firm to provide service to a consumer if he is followed by sufficiently many other consumers, and that high-quality firms always provide at least as high a service level as low-quality firms. In any stationary equilibrium, if a high-quality firm promises service in any period $\bar{s}$ to a consumer, the consumer will return the next period he enters the market, regardless of his expectations about future service: Accepting the optimal per-period outcome of high quality and high service and searching thereafter for a new firm dominates searching immediately. Thus high-quality firms can always ensure the return of a consumer by promising him service. The question is when this will be profitable.

Consider the case in which there are few wealthy consumers and many poor consumers: $\alpha$ is small and the ratio $(1-\alpha) / \alpha$ of poor to wealthy consumers is large. If consumers follow the wealthy, this means that each visit by a wealthy consumer induces future business from many poor followers (and some wealthy followers). There are two benefits to a high-quality firm from offering service. The first is the effect of "competitive pressure." If other high-quality firms offer service to the wealthy, the consumer may never return, but rather search for another firm that offers both high quality and high service. Offering service ensures that the consumer will return the next time he wants to consume, in which case the firm reaps the profit from the large number of followers that succeed him. The second effect is an "encouragement effect." Even if the consumer returns to this firm despite the absence of service, he will return more frequently if the firm offers 
service, and the business generated by his followers will increase. When there are many followers it is profitable to incur the cost of service. $^{25}$

Moreover, it is indeed optimal for high-quality firms to outbid low-quality firms in their pursuit of valuable customers. If it is profitable for a low-quality firm to provide service to a consumer, it is also profitable for a high-quality firm to provide service in order to keep the business of this consumer. We summarize the results in the following proposition. We denote the proportions of wealthy and poor as follows: $\alpha^{w}=\alpha$ and $\alpha^{p}=1-\alpha$.

Proposition 2. Let $\delta \in(\underline{\delta}, 1)$.

(i) Suppose all uninformed consumers follow consumers of type $\theta \in\{w, p\}$. If there are many consumers of the other type $\left(\alpha^{\theta}<\bar{\alpha}\right.$ for some $\left.\bar{\alpha}>0\right)$, in any stationary equilibrium consumers of type $\theta$ receive service $\left(s_{h}(\theta)=\bar{s}\right)$.

(ii) In any stationary equilibrium, either high-quality firms provide more service than low-quality firms $\left(s_{h}(\theta) \geq s_{l}(\theta)\right.$ for $\theta \in\{p, w\})$, or consumers of type $\theta$ nevertheless do not return to low-quality firms even when they offer service and high-quality firms do not.

\section{III.E. Equilibria}

With these results on optimal strategies for consumers and firms in hand, we turn to the stationary equilibria of the game. We first provide a necessary condition for equilibria when the value of service is not too large. In any such equilibrium, the poor follow the wealthy, and if service is provided, it is provided only to the wealthy. This is driven by the fact that the wealthy accumulate information faster than the poor.

Proposition 3. Let $\delta \in(\underline{\delta}, 1)$. There exists $v>u_{0}^{p}-u_{0}^{w}$ such that the following holds: If service is not too important $(\bar{s}<v)$, then in any stationary equilibrium all uninformed consumers follow wealthy consumers after their initial purchase; if service is provided, it is provided only to the wealthy.

25. A similar argument applies if there are few poor leaders, that is, if the ratio $\alpha /(1-\alpha)$ of wealthy to poor consumers is large and if the provision of service to the poor induces them to consume more frequently than the rich. In this case they will be followed and high-quality firms will find it beneficial to provide them service. 
Thus for moderate service levels the wealthy will always be the leaders. This will happen even for some levels of service that outweigh the difference in outside options. In this case, even if only the poor receive service and consume more often once they have found a high-quality firm (by Lemma 3 in the Appendix), they are not followed because they search less frequently than the wealthy when they have not found a high-quality firm. There is a partial converse to Proposition 3: The poor can arise as leaders when service is very important. If $\bar{s}$ is large and is exclusively provided to the poor, then they will consume so frequently that they find high-quality places faster than the wealthy and will be followed. The encouragement effect thus opens up the possibility of multiple equilibria in which either the rich or the poor might be followed. If one of the groups is acknowledged as the leaders, the firms might strategically provide service to this group because of the followers, which in turn supports their position as the leaders.

Whether service provision is profitable for the firms depends on the number of followers an individual has. Since $P<c$ service will only be provided when the profit generated by one's followers is sufficiently large. We establish existence and uniqueness separately for the cases when there are many or few poor. ${ }^{26}$ For some of the equilibrium analysis it is important whether consumers who are followed only by others of the same type would receive service. This cannot be the case when the survival probability $\delta$ is sufficiently high because in this case most consumers will have found a high-quality firm and very few are searching. Since the price does not cover the cost of service, it will not be profitable to provide service if a consumer only has very few followers. That is, there exists a value $\delta^{*}$ such that for survival rates greater than $\delta^{*}$, no firm would find it profitable to provide service to consumers who are only followed by consumers of their own type. $^{27}$

The following proposition establishes existence of equilibria when the ratio of poor to wealthy consumers is sufficiently large. All equilibria exhibit service only for the wealthy customers if $\delta$ is sufficiently high or service is lower than the threshold $v$ in Proposition 3.

26. We have not shown that the fixed point distribution when the rich follow themselves is unique. Also, service by low-quality firms might make no difference to the consumers' search. Therefore equilibria might not be unique, but all exhibit the properties we establish.

27. See Lemma 8 in the Appendix. 
Proposition 4. Fix $\delta \in(\underline{\delta}, 1)$ and $\bar{s}>0$. If the fraction of wealthy people is small $\left(\alpha \leq \alpha^{*}\right.$ for some $\alpha^{*} \in(0,1)$ ), then the following hold:

(i) There exist stationary equilibria in which all consumers follow wealthy consumers while searching. Consumers stop searching only when they find a high-quality firm, and high-quality firms offer service to the wealthy and not to the poor. Low-quality firms may offer service but do not attract repeat business.

(ii) All stationary equilibria are of this form if service is not too important $(\bar{s}<v)$, or if the survival rate is high $\left(\delta>\delta^{*}\right)$.

The proposition shows that firms indeed support the learning process when the service can be concentrated on sufficiently few wealthy people who achieve high visibility in the market. For all consumers the outcome is clearly preferred to a world in which service is absent. Wealthy consumers benefit directly from the service and indirectly because they obtain high quality faster. Poor customers benefit also, but only indirectly through the improved search externality provided by the wealthy. High-quality firms benefit because consumers find high-quality firms faster. However, their cost of providing service might outweigh this benefit. Low-quality firms unambiguously lose compared to a world without firms' ability to affect the consumers' search process. Service increases the informational externality between consumers, and a newborn consumer samples, on average, fewer low-quality firms before finding high quality.

As a comparison, we analyze the case in which the ratio of wealthy to poor players is reversed. If there are few poor people, there is always an equilibrium in which everybody follows the wealthy. Only if service is sufficiently important is there also a second equilibrium in which everybody follows the poor.

Proposition 5. Fix $\delta>\max \left\{\underline{\delta}, \delta^{*}\right\}$ and $\bar{s}>0$. If the fraction of poor people is small $\left(\alpha \geq \alpha^{* *}\right.$ for some $\alpha^{* *} \in(0,1)$ ), then the following hold:

(i) There exist stationary equilibria in which all consumers follow wealthy consumers while searching. Consumers stop searching only when they find a high-quality firm. High-quality firms do not offer service to any consumer. Low-quality firms may offer service but do not attract repeat business. If the importance of service is not too high $(\bar{s}<v)$, these are the only equilibria. 
(ii) There is $v^{\prime}>u_{0}^{p}-u_{0}^{w}$ such that the following holds: If service is very important $\left(\bar{s}>v^{\prime}\right)$, there also exist equilibria in which all consumers follow poor consumers while searching. Consumers stop searching only when they find a highquality firm. High-quality firms offer service to the poor and not to the wealthy. Low-quality firms may offer service but do not attract repeat business.

(iii) There do not exist stationary equilibria with other properties.

Proposition 5 demonstrates the natural advantage that the wealthy possess in information gathering. Following the wealthy is always an equilibrium, as in the absence of service it is best for everybody to follow them. Only if service is very attractive will the poor search sufficiently frequently so that following them can be worthwhile. It is worth noticing that all consumers are better off in environments in which service is provided than in environments in which no service is provided. This is immediate for the group getting the service, but even the other group benefits from a better signal. This implies here that all consumers are better off in the equilibrium where consumers follow the poor and the poor obtain service than in the equilibrium in which all follow the rich and the rich do not receive service.

Propositions 4 and 5 establish that it is the information that is revealed in the choices of the wealthier players that makes them valuable to other players and, by extension, to firms. If there are sufficiently many consumers who value this information, the wealthy are in a unique position to profit from this if service is not too valuable. Poor consumers are not substitutes for the wealthy, as their actions reveal less information than those of the wealthy, even if the visibility of the poor is much better when there are fewer of them. Note that we have effectively ruled out trigger strategies in the analysis. ${ }^{28}$ Hence, firms' decisions are primarily influenced by the per period contribution of a customer. Thus, it is not the frequency of consumption per se that allows wealthier consumers to command service, but rather the induced information that is valued by other consumers, and in turn by the firms.

28. These would have allowed richer customers to impose harsher punishment on firms, as their overall lifetime consumption is higher and their effective discount factor is higher due to more frequent consumption. 


\section{Discussion}

Although we focused on differences in income as a source of consumer heterogeneity, the model is easily amenable to other interpretations. Also, the basic model omits the discussion of interesting aspects of social interaction such as conspicuous consumption, popularity, and the importance of relative position in society. We briefly discuss these in light of examples given in the Introduction. We also consider the robustness of our results to more direct price competition and relate our results to the literature.

\section{IV.A. Interpretation of Consumer Differences}

Our interpretation of the different opportunity $\operatorname{costs} u_{0}^{w}$ and $u_{0}^{p}$ is derived from differences in income that affect the consumers' budget constraints. Alternatively, $u_{0}^{w}$ and $u_{0}^{p}$ could be taken as primitives that result from heterogeneity with respect to characteristics other than income, such as differences in tastes. If you look for a Swedish restaurant, Swedes might have a greater preference than the average consumer, that is, have lower $u_{0}$. For running shoes, runners will consume more, and good jazz places are most likely discovered by following jazz enthusiasts. For some of our examples, such as Reebok's sponsoring of local triathletes or product support to ski instructors, differences in preferences seem the relevant explanation. Although our analysis can easily handle exogenous differences, our focus on income differences stems from two observations. For normal goods, income differences will induce higher consumption for the wealthy. More importantly, in many situations income differences might be easier to infer than differences in taste. If taste heterogeneity is similar for different income categories but only income differences are observable, then the firms' treatment decisions and the consumers' decisions on whom to follow will be based on the observable characteristic.

\section{IV.B. Conspicuous Consumption}

The ability to distinguish different types of consumers is important in our framework. Even income differences are typically not observable per se, but must be inferred from some attribute, for example, from the suit one wears or the car one drives. This suggests a rational basis for conspicuous consumption. One could extend our model to include an additional good that is observable, such as clothing. By a standard signaling argument, those 
who consume our good more frequently would rationally choose to spend the money on the conspicuous good if it leads to greater service, whereas less frequent purchasers would not. In this environment the welfare of all new-born consumers-rich or poorcan be higher in the presence of conspicuous consumption despite its cost, since agents' decisions on whom to follow become more precise. These positive externalities from a more efficient search process can outweigh the deadweight loss.

\section{IV.C. Popularity}

We have assumed that consumers of the same type have the same number of followers. While this might be a reasonable assumption among anonymous consumers in day-to-day consumption settings, this clearly does not hold for our example of celebrities who receive expensive swag. Celebrities have a higher visibility than other people of similar income and-according to the logic underlying our analysis-will have more followers and are more likely to get serviced. The extent of the knowledge about the product interacts with this visibility advantage, leading to valuable gifts mainly in those areas where knowledge is perceived to be high.

\section{IV.D. The Race for Relative Position}

Our model delivers a benefit from being relatively more informed or visible than one's peers. It is the relatively richer agents that in general become market leaders and benefit from that. In this paper we do not model the competition for better relative standing, yet the environment clearly induces a race for better relative standing if income or visibility is endogenized. The strength of the incentive depends on the number of occasions in which better service is obtained by the leading group.

\section{IV.E. Fixed Price}

We took the price as being exogenously set, and identical across firms regardless of quality. Even if prices differed across firms, it is unrealistic to think that they would perfectly convey the quality of firms, and there would remain the possibility that social learning of the sort in our model would still play a role. Nevertheless it is worth discussing what the equilibria of a model such as we have laid out would look like if prices were a strategic variable rather than exogenously set. Suppose that firms chose prices strategically and that there was a symmetric equilibrium 
in which all low-quality firms set one price and all high-quality firms set a possibly different price. If the difference in quality between the high- and low-quality firms is small, there may be a separating equilibrium in which the prices of the two types of firms are not very different, and wealthy people go to high-quality firms whereas the poor go to cheaper, low-quality firms. Suppose, however, that there was little or no value to the low-quality firm; that is, even at very low prices all consumers would prefer the high-quality firm. There clearly cannot be a separating equilibrium then because low-quality firms could profitably charge the same price as high-quality firms. If all firms charge the same price, whether any single firm has an incentive to deviate depends on consumers' beliefs when they see an out-of-equilibrium price. Trivially, if consumers believe that it is a low-quality firm that deviates, such a deviating firm will attract no new customers. ${ }^{29} \mathrm{~A}$ high-quality firm that increased its price slightly could possibly retain its current customer base, since those customers know the quality and there is a cost to finding another high-quality firm. There is a limit to the increase that is possible without current customers searching for an alternative high-quality firm. There is thus a trade-off between the increase in profits a high-quality firm can obtain by raising its price to its current clientele and the lost profits from the absence of new customers. If the price at which firms pool is set sufficiently high, the second effect outweighs the first and firms find it unprofitable to increase their price.

Thus, although it is beyond the scope of this paper to formally include strategic pricing, it is reasonable to expect that the equal pricing that we assumed would characterize one equilibrium.

\section{IV.F. Related Literature}

Our work is related to two strands of literature: social learning from the choices of others, and economic analysis of social environments. For the former, the idea that consumers condition their search process on observations of others is already embedded in Nelson's (1970) idea of guided sampling in consumer search. Formal economic models have been proposed in the literature on social learning in which consumers make inferences

29. In fact, a firm that increased its price would attract no new customers even if the consumers believed that all firms were equally likely to set the higher price. 
about the quality of a good by observing what other consumers have done ${ }^{30} \mathrm{~A}$ sequence of one-time buyers who can observe the choices of their predecessors has been analyzed in Banerjee (1992), Bikhchandani, Hirshleifer, and Welch (1992) and Bose et al. (forthcoming, 2006). Smallwood and Conlisk (1979), Ellison and Fudenberg (1995), and Banerjee and Fudenberg (2004) model information transmission when many consumers move simultaneously in each period. Bolton and Harris (1999) and Bergemann and Valimaki $(1996,2000)$ analyze strategic experimentation under the assumption that a finite number of agents decide simultaneously and repeatedly. McFadden and Train (1996) consider a three-period model experimentation problem in which consumers' experience with the good is an idiosyncratic permanent draw.

These models consider ex ante identical consumers who choose among two alternatives, of which at least one has unknown characteristics. Since consumers are identical, these models abstract from the social environment in which some consumers may endogenously arise as leaders and others as followers based on their underlying characteristics. Consequently, the central point of the present paper is absent. Additionally, these papers consider a different informational problem by considering a decision between two alternative products for which agents learn the relative attractiveness over time. In the present work we consider a large number of alternatives, some of which have higher quality than others. Optimal experimentation does not rely on the relative information on one product compared to the other, but on the relative information accumulated in one group of consumers relative to the other group of consumers. This determines which group of consumers arises as market leader.

The economic analysis of social environments generally focuses on the interplay between economic forces and some social force that is not directly priced in the market. In his influential contribution, Veblen (1934) explains the purchase of certain conspicuous consumption goods for the mere reason of appearing wealthy to others. The prestige of being regarded as rich arguably has many components. The present work derives prestige endogenously from the fact that people who appear wealthy are treated better by firms because they attract additional business to them.

30. There is research in other fields on the degree to which consumer choice is influenced by other people. See Rogers (1995) for an overview of the marketing literature. 
Another reason to accumulate wealth or engage in conspicuous consumption arises if higher wealth leads to more attractive partners in the marriage market. ${ }^{31}$ The current paper can be viewed as complementary, as it establishes another channel apart from a matching market by which affluent individuals benefit. Our model is completely integrated into a market environment, yet the information externality that the lead consumers provide yields them additional benefits.

When conspicuous consumption goods are produced by a monopolist the signaling game can lead to fashion cycles. Pesendorfer (1995) shows that the monopolist first introduces a fashion to the attractive agents and then expands it slowly to the larger market before introducing a new design. Because knowledgeable agents in our model have a desire to distinguish themselves from other agents, a similar logic might apply. To the extent that fashion is correlated with higher consumption (and thus information) about other products, we would expect fashionable people to be treated better not only in the marriage market.

Becker and Murphy (2000) provide a general approach to social interaction by modeling social capital as a stock variable that acts as a complement to other choice variables. They mention informational linkage as one form of such complementarity social capital: "A person may copy the choices made by others because he feels they have superior information" (Becker and Murphy 2000, p. 10). We model this linkage explicitly and derive social prestige in terms of better treatment as well as a desire by others to follow the influential as an informational phenomenon. Our explicit formulation has the advantage of showing the links precisely and allows predictions when the environment changes. For example, changes in the relative size of the consumer groups, in the relative income of the two groups, or in the number of people who can observe a given consumer (i.e., through media broadcasting) have structural implications for the service provision in the market. Becker and Murphy also discuss other reasons to associate with certain high-status individuals, such as direct utility from being in their proximity. We conclude by laying out the differences in predictions between these explanations and ours.

31. Cole, Mailath, and Postlewaite (1995) explore conspicuous consumption as signaling. 


\section{CONCLUSION}

We laid out a model in which some consumers endogenously arise as the more informed market leaders. Their consumption choices influence the purchase decisions of the other consumers in the market. Firms strategically engage in the search process by differential provision of service. In equilibrium service accrues only to more informed groups.

There is another explanation for the phenomenon that some people are leaders in the market, based on the followers' desire to be like the leaders. For example, Becker and Murphy (2000) point out that "followers may gain acceptance and prestige by emulating the behavior of leaders." Becker and Murphy model this by incorporating social capital directly as part of the consumers' preferences but conclude that many insights are "also applicable when complementarities are due to technological or informational linkages." A similar insight applies in part to our model, in the sense that some conclusions would arise even if consumers followed the leaders for other than informational reasons. Service provision to leaders would still be warranted. Nevertheless, we think it is insightful to model the informational channel explicitly, as it sheds light on who is likely to be followed in a market environment. This leads to testable predictions that differ from other explanations.

An explanation based on the desire to be associated with the prestige of the leaders suggests that the leaders are those in superior social or economic conditions. Our baseline model yields similar predictions by identifying the wealthy and the visible as the market leaders for the case of a normal good. If the good under consideration is an inferior good, then the people being followed will be the poorer individuals. For example, it seems natural to follow professors rather than students in pursuit of a good glass of wine, but for a good beer it might be more profitable to follow the students. ${ }^{32}$ This link between the normal or inferior nature of a good and the material status of the leading group distinguishes our approach from others and can in principle be tested.

32. There are other observations that seem inconsistent with the notion of following others for reasons of association. The linguistics literature shows adoption of language patters from poor ghetto areas in residential neighborhoods. Although our analysis is silent about this issue, the issue does not conform well with the notion of preferences for association. 
In general our model predicts that those who are more knowledgeable will be leaders to the extent that they can be identified. One clearly identifiable trait is gender. If one subscribes to the idea that women still undertake a larger part of the shopping activities, our model would suggest they will tend to be leaders in the market. An informational argument seems to us more plausible to explain why females are more likely to be leaders in many product categories (Feik and Price 1987) than an argument based on association with higher social status.

Finally, an informational argument seems more plausible in business-to-business transactions, where the customers are themselves profit-maximizing firms. In our example of SAP customers it is unlikely that firms emulate others for the sake of association, but rather interpret the buying decisions as revealing about the quality of the software. The extent to which information transfer through lead consumers shapes industry competition when quality is endogenized might be a fruitful avenue for future research.

In general there might be a variety of reasons that consumers mimic the choices of others. We view the informational component as important and show how this translates into differential treatment of consumers and leadership status in a market environment.

\section{Appendix: Details of the Proofs}

LEMMA 1. Consider a consumer with opportunity cost $u_{0}$ who has consumed in the market before and draws high-quality firms with probability $\gamma$ while searching. Let $q$ be the highest quality he has yet encountered. If $\delta \in(\underline{\delta}, 1)$ and high-quality firms offer service $s$ that is at least as high as the service offered by low-quality firms, then the consumer's optimal decision rule has the following structure:

If $q=q_{l}$, he samples a new firm if current period shock $\rho \geq \hat{\rho}_{l}=u_{0}-q_{h}-s$; otherwise he does not consume. If $q=q_{h}$, then he returns to the firm with high quality if the current period shock

$$
\rho \geq \hat{\rho}_{h}=u_{0}-E(q)-\frac{\delta \gamma}{1-\delta} \int_{\hat{\rho}_{h}}^{\hat{\rho}_{l}}[1-F(\rho)] d \rho
$$

otherwise he does not consume.

Proof. We consider first the case where the consumer is promised the same service $s \in\{0, \bar{s}\}$ from every firm in every 
period. It is straightforward to extend this to the case where lowquality firms promise less. We will work with average discounted payoffs. The functional equation for sampling with recall, given that the best quality the consumer has yet encountered is $q$, and given the current shock $\rho$, can be written as

$$
\begin{aligned}
V^{C}(q, \rho)= & \max \left\{(1-\delta)(q+s+\rho)+\delta E_{\rho^{\prime}} V^{C}\left(q, \rho^{\prime}\right),\right. \\
& (1-\delta)\left(E_{q \mid \gamma}(q)+\rho\right)+\delta E_{\tilde{q} \mid \gamma} E_{\rho^{\prime}} \max \left\{V^{C}\left(q, \rho^{\prime}\right), V^{C}\left(\tilde{q}, \rho^{\prime}\right)\right\}, \\
& \left.(1-\delta) u_{0}+\delta E_{\rho^{\prime}} V^{C}\left(q, \rho^{\prime}\right)\right\},
\end{aligned}
$$

where the first line describes the utility from returning to a known firm with quality $q$, the second line random sampling, and the last line consumption of the numeraire. ${ }^{33} E_{x}$ denotes the expectation operator with regard to variable $x . x=q \mid \gamma$ refers to variable $q$ when the probability of high quality is $\gamma$. We dropped the decisionirrelevant constant $u(y-P)$.

From (1) note that $V^{C}(q, \rho)$ is weakly increasing in $q$. Therefore for $q=q_{h}$ the first line in the max-operator is larger than the second. Thus, whenever a consumer with state variable $q_{h}$ enters the market, he will return to the firm with quality $q_{h}$ rather than sample a new one. He enters the market if the taste shock is high enough, that is, higher than $\hat{\rho}_{h} \in(\rho, \bar{\rho})$ that makes the player indifferent between not consuming (line 3 in equation (1)) or going into the market (line 1), so that

$$
(1-\delta)\left(q_{h}+s+\hat{\rho}_{h}\right)+\delta E_{\rho^{\prime}} V^{C}\left(q_{h}, \rho^{\prime}\right)=(1-\delta) u_{0}+\delta E_{\rho^{\prime}} V^{C}\left(q_{h}, \rho^{\prime}\right)
$$

or $\hat{\rho}_{h}=u_{0}-q_{h}-s$. Then in any given period the ex ante probability that this player will enter the market is $\left[1-F\left(u_{0}-q_{h}-s\right)\right]$, whereas the ex ante probability of not consuming is $F\left(u_{0}-q_{h}-s\right)$. Knowing this, the expected average discounted payoff is

$$
\begin{aligned}
E_{\rho^{\prime}} V^{C}\left(q_{h}, \rho^{\prime}\right) & =\int_{\underline{\rho}}^{\bar{\rho}} \max \left\{q_{h}+s+\rho, u_{0}\right\} d F(\rho) \\
& =u_{0}+\int_{u_{0}-q_{h}-s}^{\bar{\rho}}[1-F(\rho)] d \rho,
\end{aligned}
$$

where the second equality follows from integration by parts.

33. The equation is a contraction mapping, so by standard arguments a unique solutions exists when $[\rho, \bar{\rho}]$ is bounded. When $\rho=-\infty$ this still holds because at very low taste shocks, the consumer takes the outside option, so that the shock does not affect his utility, and we can bound the payoff space. 
Now consider $q=q_{l}$. Assume that searching for a higherquality firm is preferable to returning to the low-quality firm and obtaining service in the next period. (We will show in the subsequent proof of Lemma 2 that this is indeed optimal.) The threshold $\hat{\rho}_{l}$ for the taste shock is now given by the equality of lines 2 and 3 in (1), which can be simplified to yield

$$
\frac{\delta \gamma}{1-\delta}\left[E_{\rho^{\prime}} V^{C}\left(q_{h}, \rho^{\prime}\right)-E_{\rho^{\prime}} V^{C}\left(q_{l}, \rho^{\prime}\right)\right]=u_{0}-E_{q \mid \gamma}(\tilde{q})-\hat{\rho}_{l} .
$$

Taking $\hat{\rho}_{l}$ as given, we can express the expected value as

$$
\begin{aligned}
E_{\rho^{\prime}} V^{C}\left(q_{l}, \rho^{\prime}\right)= & F\left(\hat{\rho}_{l}\right)\left[(1-\delta) u_{0}+\delta E_{\rho^{\prime}} V^{C}\left(q_{l}, \rho^{\prime}\right)\right] \\
& +\left[1-F\left(\hat{\rho}_{l}\right)\right](1-\delta)\left[E_{q \mid \gamma}(q)+E_{\rho^{\prime}}\left(\rho^{\prime} \mid \rho^{\prime} \geq \hat{\rho}_{l}\right)\right] \\
& +\left[1-F\left(\hat{\rho}_{l}\right)\right] \delta\left[\gamma E_{\rho^{\prime}} V^{C}\left(q_{h}, \rho^{\prime}\right)+(1-\gamma) E_{\rho^{\prime}} V^{C}\left(q_{l}, \rho^{\prime}\right)\right] .
\end{aligned}
$$

The first line weights the opportunity cost of consumption by the probability $F\left(\hat{\rho}_{l}\right)$ of not consuming. The term $\left[1-F\left(\hat{\rho}_{l}\right)\right]$ in the second and third lines reflects the probability of entering the market. The utility from doing so is composed of two components. Line 2 reflects the instantaneous expected value from entering the market due to quality and taste shock, whereas line 3 represents the expected continuation value after encountering a firm with high or low quality, respectively. After rearranging terms, we have

$$
\begin{aligned}
E_{\rho^{\prime}} V^{C}\left(q_{l}, \rho^{\prime}\right)= & F\left(\hat{\rho}_{l}\right) u_{0}+\int_{\hat{\rho}_{l}}^{\bar{\rho}} \rho d F(\rho)+\left[1-F\left(\hat{\rho}_{l}\right)\right] \\
& \times\left[E_{q \mid \gamma}(q)+\frac{\delta \gamma}{1-\delta}\left[E_{\rho^{\prime}} V^{C}\left(q_{h}, \rho^{\prime}\right)-E_{\rho^{\prime}} V^{C}\left(q_{l}, \rho^{\prime}\right)\right]\right] .
\end{aligned}
$$

Inserting (3) and rearranging gives

$$
\begin{aligned}
E_{\rho^{\prime}} V^{C}\left(q_{l}, \rho^{\prime}\right) & =u_{0}-\left[1-F\left(\hat{\rho}_{l}\right)\right] \hat{\rho}_{l}+\int_{\hat{\rho}_{l}}^{\bar{\rho}} \rho d F(\rho) \\
& =u_{0}+\int_{\hat{\rho}_{l}}^{\bar{\rho}}[1-F(\rho)] d \rho .
\end{aligned}
$$

Substituting (4) and (2) into (3), we obtain an implicit function characterizing the threshold shock value $\hat{\rho}_{l} \in\left(u_{0}-q_{h}-s, u_{0}-\right.$ $\left.E_{q \mid \gamma}(q)\right)$ :

$$
\hat{\rho}_{l}-u_{0}+E_{q \mid \gamma}(q)+\frac{\delta \gamma}{1-\delta} \int_{u_{0}-q_{h}-s}^{\hat{\rho}_{l}}[1-F(\rho)] d \rho=0 .
$$


By the intermediate value theorem there is a solution to this equation, and the solution is unique, as the left-hand side is strictly increasing in $\hat{\rho}_{l}$.

Finally, note that when both firms offer service $s=\bar{s}$, the customer will not return to a low-quality firm. Because service is not provided in the first period, the customer will never experience service from any low-quality firm, even if it promises to provide service should the customer return. Therefore the results also hold for the case where only high-quality firms promise service $\bar{s}$, whereas low-quality firms may not.

QED

LEMMA 2. If all firms offer service, there exists $\underline{\delta} \in[0,1)$ such that for $\delta \geq \underline{\delta}$ consumers search for high quality. If $\bar{s}<\gamma\left(q_{h}-q_{l}\right)$, consumers always search for high-quality firms; that is, $\underline{\delta}=0$.

Proof. Consider a consumer of type $\theta$ with opportunity $\operatorname{cost} u_{0}^{\theta}$ who has experienced only low-quality firms. If both types of firms offer service, the cost of searching consists of the service forgone while sampling new firms. Assume searching for a high-quality firm is not optimal, given that the best firm encountered so far is low quality and all firms offer service, so that a consumer always returns to the first firm he encounters. Similar to equation (2), the expected value at $q=q_{l}$ is then $E_{\rho^{\prime}} V^{C}\left(q_{l}, \rho^{\prime}\right)=u_{0}^{\theta}+\int_{u_{0}^{\theta}-q_{l}-\bar{s}}^{\bar{s}}[1-$ $F(\rho)] d \rho$. The condition under which returning to the low-quality firm rather than searching is optimal is then

$$
\begin{aligned}
& (1-\delta)\left(q_{l}+\bar{s}+\rho\right)+\delta E_{\rho^{\prime}} V^{C}\left(q_{l}, \rho^{\prime}\right) \\
& \quad \geq(1-\delta)\left(E_{q \mid \gamma}(q)+\rho\right)+\delta E_{\tilde{q} \mid \gamma} E_{\rho^{\prime}} \max \left\{V^{C}\left(q_{l}, \rho^{\prime}\right), V^{C}\left(\tilde{q}, \rho^{\prime}\right)\right\} .
\end{aligned}
$$

Rearranging, substitution of $E_{\rho^{\prime}} V^{C}\left(q_{l}, \rho^{\prime}\right)$ and division by $\gamma$ yield

$$
(1-\delta)\left(q_{l}-q_{h}+\frac{\bar{s}}{\gamma}\right) \geq \delta \int_{u_{0}^{\theta}-q_{h}-\bar{s}}^{u_{0}^{\theta}-q_{l}-\bar{s}}[1-F(\rho)] d \rho .
$$

Because $\int_{u_{0}^{\theta}-q_{l}-\bar{s}}^{u_{\theta}^{\theta}-q_{h}}[1-F(\rho)] d \rho>0$ and independent of $\delta$, and $\gamma>0$, there exists $\delta^{\theta}$ such that for $\delta>\delta^{\theta}$ condition (6) cannot hold, where $\delta^{\theta}$ is defined as the survival probability that solves (6) with equality. For $\bar{s}<\gamma\left(q_{h}-q_{l}\right), \delta^{\theta} \leq 0$. If $\delta>\underline{\delta} \equiv \max \left\{0, \delta^{w}, \delta^{p}\right\}$, all consumers will search for high-quality firms. This establishes Lemma 2. Note that for $\gamma \geq \lambda$ a bound $\underline{\delta}$ can be established 
independent of the exact value of $\gamma$ by finding the fixed point of the equality in (6) when $\gamma$ is replaced by $\lambda$.

QED

Let $\hat{\rho}_{l}^{p}$ and $\hat{\rho}_{h}^{p}$ be the threshold levels for a poor consumer, and let $\hat{\rho}_{l}^{w}$ and $\hat{\rho}_{h}^{w}$ be the threshold levels for a wealthy consumer. The following lemma compares these thresholds:

LEMma 3. If $\delta \in(\underline{\delta}, 1)$ and high-quality firms offer higher service $\left(s_{h}(\cdot) \geq s_{l}(\cdot)\right)$, then

(i) If $s_{h}(w) \geq s_{h}(p)$ or $\bar{s}<u_{0}^{p}-u_{0}^{w}$ then the rich consume more frequently $\left(\hat{\rho}_{l}^{w}<\hat{\rho}_{l}^{p}\right.$ and $\left.\hat{\rho}_{h}^{w}<\hat{\rho}_{h}^{p}\right)$.

(ii) Only if $s_{h}(p)>s_{h}(w)$ and $\bar{s}>u_{0}^{p}-u_{0}^{w}$, the poor consume strictly more frequently at high-quality firms $\left(\hat{\rho}_{h}^{w}>\hat{\rho}_{h}^{p}\right)$ and will consume more at low-quality firms iff $\bar{s}>v_{\gamma}$ for some $v_{\gamma}>u_{0}^{p}-u_{0}^{w}$.

Proof. The result for the threshold $\hat{\rho}_{h}$ follows directly from $\hat{\rho}_{h}^{\theta}=u_{0}^{\theta}-q_{h}-s_{h}(\theta), \theta \in\{p, w\}$. For $\hat{\rho}_{l}$, rewrite (5) as

$$
\hat{\rho}_{l}^{\theta}-u_{0}^{\theta}+E_{\gamma}(q)=-\frac{\delta \gamma}{1-\delta} \int_{u_{0}^{\theta}-q_{h}-s_{h}(\theta)}^{\hat{\rho}_{l}^{\theta}}[1-F(\rho)] d \rho
$$

and observe that the left-hand side is increasing in $\hat{\rho}_{l}^{\theta}$ and decreasing in $u_{0}^{\theta}$ and the right-hand side is decreasing in $\hat{\rho}_{l}^{\theta}$ and increasing in $u_{0}^{\theta}-s_{h}(\theta)$. For (i), if $s_{h}(w) \geq s_{h}(p)$ or $\bar{s}<u_{0}^{p}-u_{0}^{w}$, the wealthy have lower $u_{0}^{\theta}$ and $u_{0}^{\theta}-s_{h}(\theta)$; therefore their threshold $\hat{\rho}_{l}^{w}$ must be lower for the equality to hold. For (ii), if $u_{0}^{p}-s_{h}(p) \approx u_{0}^{w}-s_{h}(w)$, then $\hat{\rho}_{l}^{w}<\hat{\rho}_{l}^{p}$ because $u_{0}^{w}<u_{0}^{p}$. Because $\hat{\rho}_{l}^{p}$ is by (5) strictly increasing and unbounded in $\bar{s}$ when $s_{h}(p)-s_{h}(w)=\bar{s}$ but $\hat{\rho}_{l}^{h}$ is constant, there exists a unique $v_{\gamma}$ such that $\hat{\rho}_{l}^{w}=\hat{\rho}_{l}^{p}$ if $\bar{s}=v_{\gamma}$.

QED

Before turning to the proof of Proposition 1, it will be necessary to establish the steady state equations. Assume all consumers who purchase at least once draw a high-quality firm with probability $\gamma$ when they choose a new firm. Treat $\gamma$ as exogenous for now. Those consumers that have not purchased draw a high-quality firm with probability $\lambda$ at their first time of consumption. We are interested in the fraction of consumers purchasing in a given period who consume at high-quality firms. Call this fraction $\gamma^{\theta}$, where $\theta \in\{w, p\}$. To calculate $\gamma^{\theta}$, we consider each group individually. We focus on the wealthy, but the derivations for the poor are analogous when $w$ is replaced with $p$. To derive the stationary distribution we must keep track of the proportion of wealthy consumers whose best quality encountered so far is $q_{l}$, 
$q_{h}$, or $\emptyset$, respectively, where $\emptyset$ stands for those who have not yet consumed. In period $t$ denote these by $n_{l}^{w, t}, n_{h}^{w, t}$, and $n_{\emptyset}^{w, t}$.

Let $A^{w} \equiv\left[1-F\left(\hat{\rho}_{\emptyset}^{w}\right)\right], B^{w} \equiv 1-F\left(\hat{\rho}_{l}^{w}\right)$, and $C^{w} \equiv\left[1-F\left(u_{0}^{w}-\right.\right.$ $\left.q_{h}-s_{h}(w)\right)$ ] denote the frequency of consumption for a newborn consumer, a consumer who has found a low-quality, and a consumer who has found a high-quality firm, respectively. The latter two were derived in Lemma 1; the threshold $\hat{\rho}_{\emptyset}^{w}$ is analytically complicated, ${ }^{34}$ but our specification that in addition to the newborn, all consumers prior to their first purchase lack information about other market participants eliminates $F\left(\hat{\rho}_{\emptyset}^{w}\right)$ in the derivation of $\gamma^{w}$. By standard arguments, we obtain the following laws of motion:

$$
\begin{aligned}
& n_{\emptyset}^{w, t+1}=(1-\delta)+\delta\left(1-A^{w}\right) n_{\emptyset}^{w, t} \\
& n_{l}^{w, t+1}=\delta A^{w}(1-\lambda) n_{\emptyset}^{w, t}+\delta B^{w}(1-\gamma) n_{l}^{w, t}+\delta\left(1-B^{w}\right) n_{l}^{w, t}, \\
& n_{h}^{w, t+1}=\delta A^{w} \lambda n_{\emptyset}^{w, t}+\delta B^{w} \gamma n_{l}^{w, t}+\delta n_{h}^{w, t} .
\end{aligned}
$$

The first equation includes the newborn players and all other consumers that have not consumed yet. The second includes all consumers that were uninformed and sampled a low quality, and all those with low qualities that sampled a low-quality firm or did not consume at all. The third includes all consumers that have sampled a high-quality firm. Stationarity is characterized by $n_{\omega}^{w, t^{\prime}}=n_{\omega}^{w, t}=n_{\omega}^{w}$ for all $t$ and $t^{\prime}$ and $\omega \in\{\emptyset, l, h\}$. We can use equations (7) to get

$$
\begin{aligned}
& n_{\emptyset}^{w}=\frac{(1-\delta)}{1-\delta+\delta A^{w}}, \quad n_{l}^{w}=\frac{\delta n_{\emptyset} A^{w}(1-\lambda)}{1-\delta+\delta \gamma B^{w}}, \\
& n_{h}^{w}=\frac{\delta n_{\emptyset} A^{w}\left[(1-\delta) \lambda+\delta \gamma B^{w}\right]}{(1-\delta)\left(1-\delta+\delta \gamma B^{w}\right)} .
\end{aligned}
$$

Because $\gamma^{w}$ represents the fraction of wealthy consumers who consumed in a period who have found a high-quality firm, we must find the measure of consumers who actually consume in any given period. Denote by $\varphi_{l}^{w}\left(\varphi_{h}^{w}\right)$ the measure of wealthy consumers who consume at low-quality (high-quality) firms in any given period

34. For a given $\gamma$, the taste shock $\hat{\rho}_{\emptyset}^{w}$ is characterized by the indifference of the customer between going into the market and sampling a random firm vs. taking his outside option. If he goes into the market, his continuation payoff $E V_{\rho^{\prime}}\left(q, \rho^{\prime}\right)$ is given in (2) and (4). Let $X=\lambda\left[(1-\delta) q_{h}+\delta E V_{\rho^{\prime}}\left(q_{h}, \rho^{\prime}\right)\right]+(1-\lambda)[(1-$ $\left.\delta) q_{l}+\delta E V_{\rho^{\prime}}\left(q_{l}, \rho^{\prime}\right)\right]$; then $\hat{\rho}_{\emptyset}^{w} \in(\underline{\rho}, \bar{\rho})$ is characterized by $\left[1-\delta F\left(\hat{\rho}_{\emptyset}^{w}\right)\right]\left[(1-\delta) \hat{\rho}_{\emptyset}^{w}+\right.$ $X]=(1-\delta) u_{0}^{w}+\delta\left[\left(1-F\left(\hat{\rho}_{\emptyset}^{w}\right)\right) X+\int_{\hat{\rho}_{\emptyset}^{w}}^{\bar{p}} \rho d F(\rho)\right]$. 
in the steady state. In any period $n_{\emptyset}^{w}$ consumers purchase with probability $A^{w}$ and draw a low-quality firm with probability (1 $\lambda$ ), and $n_{l}^{w}$ consumers purchase with probability $B^{w}$ and draw a low-quality firm with probability $(1-\gamma)$. Thus we have

$$
\varphi_{l}^{w}=n_{\emptyset}^{w} A^{w}(1-\lambda)+n_{l}^{w} B^{w}(1-\gamma) .
$$

For $\varphi_{h}^{w}$, we have similar terms for the uniformed and unsatisfied players, plus an additional term for the $n_{h}^{w}$ consumers with frequency of consumption $C^{w}$. Therefore

$$
\varphi_{h}^{w}=n_{\emptyset}^{w} A^{w} \lambda+n_{l}^{w} B^{w} \gamma+n_{h}^{w} C^{w} .
$$

Using $\gamma^{w}=\frac{\varphi_{h}^{w}}{\varphi_{l}^{w}+\varphi_{h}^{w}}$ and $n_{\emptyset}^{w}, n_{l}^{w}$ and $n_{h}^{w}$ from equations (8), we get after rearranging

$$
\gamma^{w}=1-\frac{\left[1-\delta+\delta B^{w}\right][1-\lambda]}{1-\delta+\delta(1-\lambda+\gamma) B^{w}+\left[\delta \lambda+\frac{\delta^{2}}{1-\delta} B^{w} \gamma\right] C^{w}} .
$$

Proof of Proposition 1. Consider $\theta \in\{p, w\}$. For $\gamma \in(\lambda, 1)$ we have $\gamma^{\theta}>\lambda$ because the multiplier of $(1-\lambda)$ in (11) is strictly smaller than 1 . To compare $\gamma^{w}$ and $\gamma^{p}$ consider the general form of (11) with $w$ replaced by $\theta$, where $\theta \in\{p, w\}$. Some algebra reveals that $\left(\partial \gamma^{\theta} / \partial B^{\theta}\right)>0$ iff $(\gamma-\lambda) \delta(1-\delta)+\delta^{2}(\gamma-\lambda) C^{\theta}>0$, which holds since $\gamma \in(\lambda, 1)$. Clearly $\left(\partial \gamma^{\theta} / \partial C^{\theta}\right)>0$. Therefore $\gamma^{w}>\gamma^{p}$ if $C^{p}<C^{w}$ and $B^{p}<B^{w}$, which is by Lemma 3 the case for $s_{h}(w) \geq s_{h}(p)$ or $\bar{s}<u_{0}^{p}-u_{0}^{w}$. By the same lemma $s_{h}(p)-s_{h}(w)=$ $\bar{s}>v_{\gamma}$ implies $C^{p}>C^{w}$ and $B^{p}>B^{w}$, which in turn implies $\gamma^{w}<$ $\gamma^{p}$. In the intermediate case of $s_{h}(p)-s_{h}(w)=\bar{s} \in\left(u_{0}^{p}-u_{0}^{w}, v_{\gamma}\right)$, we have $C^{p}>C^{w}$ but $B^{p}<B^{w}$. If $s_{h}(p)-s_{h}(w) \approx u_{0}^{p}-u_{0}^{w}$, then $C^{p} \approx$ $C^{w}$ but $B^{p}<B^{w}$, and therefore $\gamma^{w}>\gamma^{p}$. If $s_{h}(p)-s_{h}(w) \approx v_{\gamma}$, then $C^{p}>C^{w}$ but $B^{p} \approx B^{w}$, and therefore $\gamma^{w}<\gamma^{p}$. If $s_{h}(p)-s_{h}(w)=\bar{s} \in$ $\left(u_{0}^{p}-u_{0}^{w}, v_{\gamma}\right)$, an increase in $\bar{s}$ increases $C^{p}$ and $B^{p}$ but leaves $C^{w}$ and $B^{w}$ unchanged, and there exists a unique $\hat{v}_{\gamma} \in\left(u_{0}^{p}-u_{0}^{w}, v_{\gamma}\right)$ for which $s_{h}(p)-s_{h}(w)=\hat{v}_{\gamma}$ implies $\gamma^{w}<\gamma^{p}$.

Note that equation (11) defines function $\gamma^{w}$ as a function of $\gamma$, and we can write $\gamma^{w}(\gamma)$. Similarly, $\gamma^{p}(\gamma)$ can be defined by replacing $w$ by $p$ in equation (11).

Lemma 4. There exists a fixed point $\gamma^{\theta} \gamma=\gamma, \gamma \in(\lambda, 1)$, such that equation (5) is also satisfied, $\theta \in\{w, p\}$.

Proof. Consider first the case where the uninformed wealthy consumers follow other wealthy consumers; that is, $\theta=w$. 
Consider the mapping $\tau:[\lambda, 1] \times\left[u_{0}^{w}-q_{h}-\bar{s}, u_{0}^{w}-q_{l}\right] \rightarrow[\lambda, 1] \times$ $\left[u_{0}^{w}-q_{h}-\bar{s}, u_{0}^{w}-q_{l}\right]$ such that

$$
\tau(\gamma, \hat{\rho})=\left(\begin{array}{c}
\tau_{1}\left(\gamma, \hat{\rho}_{l}\right) \\
\tau_{2}\left(\gamma, \hat{\rho}_{l}\right)
\end{array}\right) .
$$

Let $\tau_{1}\left(\gamma, \hat{\rho}_{l}\right)$ equal the right-hand side of (11). For $\gamma \in[\lambda, 1]$ this implies $\tau_{1}\left(\gamma, \hat{\rho}_{l}\right) \in(\lambda, 1)$. Similar to equation (5), let $\tau_{2}\left(\gamma, \hat{\rho}_{l}\right)=\tau_{2}(\gamma)$ be implicitly defined by

$$
\tau_{2}(\gamma)=u_{0}^{\theta}-E_{q \mid \gamma}(q)-\frac{\delta \gamma}{1-\delta} \int_{u_{0}^{w}-q_{h}-s_{h}(\theta)}^{\tau_{2}(\gamma)}[1-F(\rho)] d \rho .
$$

The function $\tau$ is continuous. For $\tau_{1}$ this is easy to see. For $\tau_{2}$, note that in (12) $\gamma$ as a function of $\tau_{2}$ is continuous and strictly monotone. Therefore $\tau_{2}(\gamma)$ is also continuous. Domain and codomain of $\tau$ are identical, and they are compact subsets of $\Re^{2}$. By Brouwer's fixed point theorem there exists a fixed point of $\tau$. A similar fixed point argument applies to the case where the poor follow the poor, only with $w$ replaced by $p$.

QED

Proof of Proposition 2. In a stationary equilibrium, a consumer who purchases from a firm has the same expected number of followers in every period. Thus, the benefit to a firm from a single visit of a particular customer is the following: The customer pays price $P$, potentially receives service at cost $c>P$, and induces the expected discounted lifetime equilibrium profit that the firm receives from his next-period followers. Call this benefit П. П is an equilibrium object that depends on the strategies of the firm in question as well as the strategies of other firms and consumers. If a firm deviates and promises $s^{\prime}$ instead of the equilibrium promise $s$, the benefit of the next return visit is $\Pi-\left(c\left(s^{\prime}\right)-c(s)\right)$. Because in a stationary equilibrium after a one-shot deviation the continuation game is unchanged once the customer returns, only the immediate cost of service changes from $c(s)$ to $c\left(s^{\prime}\right)$. In particular, the behavior of the customer once he returns, as well as the behavior of the followers, is unchanged. Yet it might delay the consumer's return, as now consumption is less valuable compared to the opportunity cost of consumption. If the consumer switches to a competitor, $\Pi-\left(c\left(s^{\prime}\right)-c(s)\right)$ may in fact never be realized.

We will derive $\Pi$ for the following case: All consumers follow the wealthy, the wealthy are promised service by high-quality and not by low-quality firms, and no firm promises service to the poor. 
The benefit of a wealthy consumer to a high-quality firm is

$$
\begin{aligned}
& \Pi^{w h}=P-c+\beta N_{w} \Pi^{w h}\left[1+\frac{\delta \beta}{1-\delta \beta}\left(1-F\left(u_{0}^{w}-q_{h}-s\right)\right)\right]+\beta N_{w} c \\
& (13) \quad+\beta N_{p} P\left[1+\frac{\delta \beta}{1-\delta \beta}\left(1-F\left(u_{0}^{p}-q_{h}\right)\right)\right] .
\end{aligned}
$$

It comprises the wealthy consumer's own contribution $P-c$, plus the lifetime contributions of his followers. The expected number $N_{w}$ of wealthy followers in the next period is given by the number of consumers who are searching in that period divided by the number of all wealthy who are consuming; that is,

$$
N_{w}=\frac{\varphi_{l}^{w}}{\varphi_{l}^{w}+\varphi_{h}^{w}}=1-\gamma .
$$

In subsequent periods they consume with probability $1-F\left(u_{0}^{w}-\right.$ $\left.q_{h}-\bar{s}\right)$ conditional on surviving. They generate benefit $\Pi^{w h}$ every time they visit. These followers do not get service on their first visit to the firm. Finally, there are

$$
N_{p}=\frac{\varphi_{l}^{p}}{\varphi_{l}^{w}+\varphi_{h}^{w}} \frac{1-\alpha}{\alpha}
$$

poor consumers who follow in the next period. In every subsequent period they consume with probability $1-F\left(u_{0}^{p}-q_{h}\right)$ if they survive. They generate benefit $P$ each time they consume. For other cases $\Pi$ can be constructed analogously.

We will prove Proposition 2 in Lemmas 5, 6, and 7. The first of these lemmas establishes that a leader's benefit to a firm can be arbitrarily high if he is followed by sufficiently many customers of the other type. To state the lemma, recall that $\alpha^{w}=\alpha$ and $\alpha^{p}=1-\alpha$.

Lemma 5. Fix $M>0$. Assume type $\theta$ customers are being followed by consumers of the other type $\bar{\theta} \neq \theta$. Assume the type $\bar{\theta}$ consumers do not receive service. Then for any $\delta \in(0,1)$ there exists $\bar{\alpha}>0$, such that for all $\alpha^{\theta} \in(0, \bar{\alpha})$ the benefit $\Pi$ of a type $\theta$ customer to a firm is greater than $M$ (independent of the service strategies toward type $\theta$ consumers).

Proof. Because the type $\bar{\theta}$ followers do not receive service, they will search for high-quality firms. The value of next-period type $\bar{\theta}$ 
followers to any firm due to a visit by a leader is at least

$$
(1-\delta) \alpha^{\bar{\theta}}\left[1-F\left(u_{0}^{\bar{\theta}}-q_{l}\right)\right]^{2}(1-\lambda) \delta \frac{1}{\alpha^{\theta}} P \beta .
$$

In every period there will be $(1-\delta) \alpha^{\bar{\theta}}$ newborn followers of type $\bar{\theta}$ who go into the market with probability greater than $\left[1-F\left(u_{0}^{\bar{\theta}}-\right.\right.$ $q)]>0$, do not find a sufficiently good firm with probability $(1-\lambda)$, survive another period with probability $\delta$, and consume again with probability of at least $\left[1-F\left(u_{0}^{\bar{\theta}}-q_{l}\right)\right]$. This time they follow a leader who was in the market the previous period, of whom there are at most $\alpha^{\theta}$. They pay price $P$, and because they follow a period later than the visit of the leader, their value is discounted by $\beta$. The expression goes to infinity as $\alpha^{\theta}$ goes to zero. The firm might incur service costs for the leader, but these are easily offset by his immediate type $\bar{\theta}$ followers. The leader might also have followers of his own type, which themselves bring a benefit larger than $M$ in the period after and will therefore increase this consumers benefit even more.

QED

The following lemma shows that a high-quality firm will provide service when the customer's profit contribution is sufficiently large. Let $\Pi^{\theta h}$ denote the benefit of one-time consumption of a type $\theta$ consumer for a high-quality firm.

Lemma 6 . There exists $M>0$ such that in any stationary equilibrium with $\Pi^{\theta h}>M$, a high-quality firm will promise service $\bar{s}$ in any period to type $\theta$ consumers.

Sketch of Proof. We distinguish two cases. Case 1: A type- $\theta$ customer of a high-quality firm would search for another firm if he had not been promised service in the last period. Then for $\Pi^{\theta h}>$ $M=c$ promising service is optimal, because by promising service the firm retains the business of this consumer and gains $\Pi^{\theta h}-c$ when he returns. Case 2: The consumer would return to the firm even if he had not been promised service during his last visit. The consumer will enter the market with lower probability than if service had been promised. This implies that his next visit will be delayed in expectation. Due to discounting and potential death of the consumer, this delay is associated with a loss proportional to $\Pi^{\theta h}$. Therefore, for $\Pi^{\theta h}$ large enough it is always profitable to avoid the delay costs by promising service, even though service is costly. A precise proof based on the one-shot-deviation-principle can be found in Kircher and Postlewaite (2007). 
Finally, we show that high-quality firms will always outbid low-quality firms:

Lemma 7. Let $\delta \in(\underline{\delta}, 1)$. In any stationary equilibrium, either $s_{h}(\theta) \geq s_{l}(\theta)$ for $\theta \in\{p, w\}$, or $s_{h}(\theta)<s_{l}(\theta)$, but type $\theta$ consumers nevertheless do not return to low-quality firms.

Proof. Assume $s_{h}(\theta)<s_{l}(\theta)$ and type $\theta$ customers stop searching when they have found a low-quality firm. We will discuss the case of the wealthy, that is, $\theta=w$ (note that the discussion holds for the poor when the roles of wealthy and poor are reversed). Because the wealthy receive service, they have to have followers. The poor would follow them only if the poor also got service from lowquality firms and not from high-quality firms, as only then they have an incentive to search for low qualities. (If the poor searched for high qualities, they would not want to follow the wealthy who stop searching at low qualities.) Yet if the poor follow the wealthy, the poor will not get any service, because $P>c$.

To get service, wealthy customers must be followed by someone, and the only candidates are other wealthy consumers who are still searching. If each wealthy consumer is followed by some expected number $N_{w}$ of other wealthy consumers (and by none of the poor), the candidate equilibrium profit contribution $\Pi^{w l}$ that a low-quality firm receives from a one-time visit of a wealthy customer is

$$
\Pi^{w l}=P-c+\beta N_{w} \Pi^{w l}\left[1+\frac{\delta \beta}{1-\delta \beta}\left(1-F\left(u_{0}^{w}-q_{l}-\bar{s}\right)\right)\right]+\beta N_{w} c .
$$

The derivation is similar to that of equation (13). In the stationary setting

$$
\beta N_{w}\left[1+\frac{\delta \beta}{1-\delta \beta}\left(1-F\left(u_{0}^{w}-q_{l}-\bar{s}\right)\right)\right]<1 .
$$

Solving for $\Pi^{w l}$ yields

$$
\Pi^{w l}=\frac{P-c+\beta N_{w} c}{1-\beta N_{w}\left[1+\frac{\delta \beta}{1-\delta \beta}\left[1-F\left(u_{0}^{w}-q_{l}-\bar{s}\right)\right]\right]} .
$$

For this to be an equilibrium, $\Pi^{w l} \geq 0$. Consider first the case where $\Pi^{w l}>0$, that is, $P-c+\beta N_{\theta} c>0$. In this case high-quality firms have an incentive to deviate and also offer service to wealthy 
consumers, which upsets the equilibrium. To see this, note that for a high-quality firm the candidate equilibrium profit contribution from a wealthy consumer is zero after the first period of consumption because he does not consume there again. Deviating and offering service to the customer and all his followers generates the profit contribution

$$
\Pi^{\prime}=P-c+\beta N_{w} \Pi^{\prime}\left[1+\frac{\delta \beta}{1-\delta \beta}\left(1-F^{\prime}\right)\right]+\beta N_{w} c,
$$

where $1-F^{\prime}$ is the probability with which a wealthy customer that is offered service is returning. Because $\bar{\rho}>u_{0}^{w}-q_{h}-\bar{s}$, the frequency $1-F^{\prime}>0$. Because $P-c+\delta N_{w} c>0$, it follows that $\Pi^{\prime}>0 .{ }^{35}$ But then high-quality firms would offer service.

Consider now the case $\Pi^{w l}=0$, that is, $P-c+\beta N_{w} c=0$. Therefore, low-quality firms are indifferent between promising service or not. In this case high-quality firms are also indifferent between offering service or not. By the tie-breaking rule we employed, both types of firms offer service. ${ }^{36}$ However, wealthy consumers then do not search for low-quality firms; consequently high-quality firms offer service, and wealthy customers would not search for low qualities.

QED

This completes the proof of Proposition 2.

LEMma 8. Consider a candidate equilibrium in which type $\theta$ consumers are followed (only) by other type $\theta$ consumers that are still searching. There exists $\delta^{*} \in(0,1)$ such that for $\delta>\delta^{*}$ no firm would find it profitable to promise service to type $\theta$ consumers.

Proof. If $\theta=r$ and high-quality firms would provide service, we get a contradiction by considering equation (13) with the number of poor followers $N_{p}=0$ and $N_{w}=1-\gamma$, where $\gamma$ is the

35. Since this is a deviation from a steady state,

$$
\beta N_{w} \Pi^{\prime}\left[1+\frac{\delta \beta}{1-\delta \beta}\left(1-F^{\prime}\right)\right]
$$

might be larger than 1 , in which case the discounted profit from offering service is unbounded.

36 . This is the only place we use this tie-breaking rule. The result holds also when we employ the assumption that firms do not offer service when indifferent. The point is that both types of firms resolve indifference the same way. Moreover, simple restrictions such as a high survival rate $\delta$, a high cost-price wedge $c-P$, or a modest service influence $\bar{s}$ would also guarantee the result, as they rule out indifference. 
fixed point to equation (11). Because $1-\gamma$ converges to 1 and $(1-\gamma) /(1-\delta)$ to $1 /\left(1-F\left(u_{0}^{w}-q_{h}-\bar{s}\right)\right)$ for $\delta$ converging to 1 , the per-period profit including followers is $\Pi \approx(P-c)<0$ for $\delta$ large. This contradicts a profit-maximizing service offer by high-quality firms. An analogous argument establishes that if high-quality firms do not offer service, a high-quality firm that offers service would make a loss. Similarly, we can show that low-quality firms would make a loss if they offered service, and extend the argument to $\theta=w \cdot{ }^{37}$

QED

Proof of Proposition 3. By Proposition 2, high-quality firms provide weakly higher service than do low-quality firms. Therefore, all consumers search for high-quality firms (see Lemma 2). That is, all consumers, wealthy and poor, will in equilibrium follow the distribution that places the highest weight on high-quality firms. By Proposition 1, $\bar{s}<\hat{v}_{\gamma}$ ensures that all consumers will follow the wealthy, even if the poor receive the service. Because $P<c$, service is only provided (i.e., promised and then delivered) to players who have followers. Therefore, in equilibrium only the wealthy can receive service. Although $\hat{v}_{\gamma}$ depends on $\gamma$, one can show that it is bounded away from $u_{0}^{p}-u_{0}^{w}$ for all $\gamma \geq \lambda$. QED

Proof of Proposition 4. Assume all players follow the wealthy when searching. Then the poor will never be promised service by any firm that expects repeat business, because $P<c$ and the firm would make a loss by doing so. The wealthy will be promised service by all high-quality firms. These firms can induce the consumer to return by offering service. For $\alpha^{*}$ small enough, Proposition 2 establishes that this will be the only choice that does not have a profitable deviation. Because high-quality firms offer service, low-quality firms are never repeatedly visited by a wealthy player (see Lemma 2). It is immediate that all players have an incentive to follow the wealthy: because $s_{h}(w) \geq s_{h}(p)$, by Proposition 1 $\gamma^{w}>\gamma^{p}>\lambda$, and following the wealthy is better than following the poor or sampling randomly.

For $\bar{s}<v$ no other equilibria exist, as by Proposition 3 all players follow the wealthy and the assumption of the prior paragraph is fulfilled. If $\delta>\delta^{*}$, it is not profitable to provide service to the poor if they are followed only by other poor consumers. If $\alpha^{*}$ is sufficiently small, then each poor consumer can only have

37. The argument remains valid even when $\beta=\delta$, that is, the firms' discount factor is also large. 
a negligible number of wealthy followers, and providing service to the poor remains unprofitable even if all consumers follow the poor. If the poor do not receive service, they prefer to follow the wealthy, and again the assumption of the prior paragraph is fulfilled.

QED

Proof of Proposition 5. Assume all consumers follow the wealthy. Because $\delta>\delta^{*}$, the wealthy do not receive service due to wealthy followers, and $\alpha^{* *}$ small enough assures there will not be sufficient poor followers to warrant service. ${ }^{38}$ Also, the poor do not get service. Proposition 1 then establishes $\gamma^{w}>\gamma^{p}>\lambda$, and everybody follows the poor. By Proposition 3, for $\bar{s}<v$ there cannot be any other stationary equilibria in which the wealthy are not being followed.

Consider a stationary equilibrium in which the poor do not follow the wealthy. It must then be the case that the wealthy follow the poor. If the wealthy did not follow the poor, the poor would not receive service, and everybody would follow the wealthy as in the previous paragraph. If the wealthy follow the poor, then by Lemma 2 high-quality firms would indeed want to provide service to the poor. Yet the wealthy will only follow the poor if $\gamma^{p} \geq \gamma^{w}$. By Proposition 3 this only happens for $\bar{s} \geq \hat{v}_{\gamma^{p}}$. Because $\gamma^{p}$ is bounded away from one for all $\bar{s}$ because some newborns are always searching, it is easy to see that $\hat{v}_{\gamma^{p}}$ is bounded. Therefore there exists $v^{\prime}$ such that $\bar{s} \geq v^{\prime}$ implies $\gamma^{p} \geq \gamma^{w}$.

QED

University of PenNSYLVANIA

UNIVERSITY OF PENNSYLVANIA

\section{REFERENCES}

Assael, Henry, Consumer Behavior and Marketing Action, $2^{\text {nd }}$ ed. (Boston: Kent Publishing Company, 1984).

Banerjee, Abhijit, "A Simple Model of Herd Behavior," Quarterly Journal of Economics, 107(3) (1992), 797-817.

Banerjee, Abhijit, and Drew Fudenberg, "Word-of-Mouth Learning," Games and Economic Behavior, 46 (2004), 282-303.

Becker, Gary S., and Kevin M. Murphy, Social Economics: Market Behavior in a Social Environment (Cambridge, MA: Harvard University Press, 2000).

Bergemann, Dirk, and Juuso Valimaki, "Learning and Strategic Pricing," Econometrica, 64(5) (1996), 1125-1149.

38. The profit contribution of poor followers is given by the second line in (13) in the Appendix. For a given $\delta$, the measure of poor agents that consume low quality relative to the measure that consume either high or low quality is independent of $\alpha$ and bounded, which implies that the number of poor followers (and thus their profit contribution) converges to zero as $\alpha$ converges to one. 
__ "Experimentation in Markets," Review of Economic Studies, 67 (2000), 213234.

Bikhchandani, Sushil, David Hirshleifer, and Ivo Welch, "A Theory of Fads, Fashion, Custom, and Cultural Change as Informational Cascades," Journal of Political Economy, 100(5) (1992), 992-1026.

Bolton, Patrick, and Christopher Harris, "Strategic Experimentation," Econometrica, 67(2) (1999), 349-374.

Bose, Sabir, Gerhard Orosel, Marco Ottaviani, and Lise Vesterlund, "Monopoly Pricing in the Binary Herding Model," Economic Theory (forthcoming).

_- "Dynamic Monopoly Pricing and Herding," Rand Journal of Economics, 37(4) (2006), 910-928.

Burnkrant, Robert E., and Alain Cousineau, "Informational and Normative Social Influence in Buyer Behavior," Journal of Consumer Research, 2 (1975), 206215.

Chaney, Isabella M., "Opinion Leaders as a Segment for Marketing Communication," Marketing Intelligence and Planning, 19(5) (2001), 302-308.

Cohen, Joel B., and Ellen Golden, "Informational Social Influence and Product Evaluation," Journal of Applied Psychology, 56 (1972), 54-59.

Cole, Harold L., George J. Mailath, and Andrew Postlewaite, "Incorporating Status Concern in Economic Models," Quarterly Review of the Minneapolis Federal Reserve Bank, 19 (1995), 12-21.

Ellison, Glenn, and Drew Fudenberg, "Word-of-Mouth Communication and Social Learning," Quarterly Journal of Economics, 110(1) (1995), 93-125.

Engel, James F., Roger D. Blackwell, and Paul W. Miniard, Consumer Behavior, $8^{\text {th }}$ ed. (Fort Worth, TX: Dryden Press, 1995).

Feik, Lawrence F., and Linda L. Price, "The Market Maven: A Diffuser of Marketplace Information," Journal of Marketing, 43 (1987), 58-67.

Foster, Andrew F., and Mark R. Rosenzweig, "Learning by Doing and Learning from Others: Human Capital and Technical Change in Agriculture," Journal of Political Economy 103(6) (1995), 1176-1209.

German Ski Instructor Association, "Ausrustüngsangebot fur Schneesport-Profis 2006-07," Snow Sport, 5/2005-06 (2006).

Hoyer, Wayne D., and Deborah J. Macinnis, Consumer Behavior (Boston: Houghton Mifflin, 2001).

Kircher, Philipp, and Andrew Postlewaite, "Technical Note on 'Strategic Firms and Endogenous Consumer Emulation," mimeo, University of Pennsylvania, April 2007.

Martin, Elizabeth, "Cultural Images and Different Varieties of English in French Television Commercials," English Today, 72(18) (2002), 8-20.

McDonald, Mark A., and George R. Milne, Cases in Sport Marketing (London: Jones and Bartlett, 1999).

McFadden, Daniel L., and Kenneth E. Train, "Consumers' Evaluation of New Products: Learning from Self and Others," Journal of Political Economy, 104(4) (1996), 683-703.

Mobius, Markus M., and Paul Niehaus, "Social Learning and Consumer Demand," mimeo, Harvard University (2005).

Nelson, Phillip, "Information and Consumer Behavior," Journal of Political Economy, 78(2) (1970), 311-329.

Pesendorfer, Wolfgang, "Design Innovation and Fashion Cycles," American Economic Review, 85(4) (1995), 771-792.

Robertson, Thomas S., Joan Zielinski, and Scott Ward, Consumer Behavior (Glenwood, IL: Scott, Foresman and Company, 1984).

Rogers, Everett M., Diffusion of Innovation, $4^{\text {th }}$ ed. (New York, NY: Free Press, 1995).

Royal Warranty Holders Association, "The Royal Warrant Today" (www. royalwarrant.org/Today.asp, accessed October 27, 2006).

SAP, “Top Performers: SAP Customer Successes" (www.sap.com/usa/industries/ customersuccess.epx, accessed October 2, 2006).

Sims, J. T., "Comparison of Consumer Behavior Conformity and Independence between Blacks and Whites: An Exploratory Study," Proceedings of Second Annual Conference of the Association of Consumer Research (1971). 
Smallwood, Dennis, and John Conlisk, "Product Quality in Markets Where Consumers are Imperfectly Informed," Quarterly Journal of Economics, 93(1) (1979), 1-23.

Veblen, Thorstein, The Theory of the Leisure Class: An Economic Study of Institutions (New York: Modern Library, 1934).

Venkatesan, M., "Experimental Study of Consumer Behavior-Conformity and Independence," Journal of Marketing Research, 3 (1966), 384-387.

Wolinsky, Asher, "Information Revelation in a Market with Pairwise Meetings," Econometrica, 58(1) (1990), 1-23. 